\title{
Personalization Strategies Implementation for Malaysian M-Government Services
}

\author{
Noor Suriana Abu Bakar ${ }^{1,2 *}$ and Azizah Abdul Rahman ${ }^{2}$ \\ 'Faculty of Computer and Mathematical Sciences, Universiti Teknologi MARA Melaka, Malaysia; \\ suriana_su@melaka.uitm.edu.my \\ ${ }^{2}$ Faculty of Computing, Universiti Teknologi Malaysia, Malaysia; azizahar@utm.my
}

\begin{abstract}
Objectives: The purpose of this study was to examine citizens' level of use towards m-Government services and to suggest the personalization strategies that help the government to provide better services to the citizens. Methods/Statistical Analysis: The survey method was obtained in this study to know the level of used m-Government among citizens and to know the user's needs/interest towards m-government services. For data collection purposes, 200 questionnaires were distributed to respondent who have used m-Government services at five selected agencies which are JPN, JPA, KPDNKK, MOE and MPM. Findings: With the increasing rate of services offered by the government annually, it makes it difficult for citizens to find the appropriate services based on their needs. Personalization is one of the alternative solutions to deliver the right services to citizens and can reduce the information overload problems. From the analysis undertaken, it was found that the levels of use of m-Government services are encouraging but most respondents utilized only one service in each transaction. They also do not know what services that are appropriate for them and tailor to their needs and requirements. The results also indicated that the highest use of $\mathrm{m}$-Government is among younger generation, where it provides an effective way to reach out to people in all areas and enables them to obtain information easier. Application/ Improvements: Finally, the government should take immediate steps to provide the personalization strategies to encourage the usage of $\mathrm{m}$-Government services among citizens.
\end{abstract}

Keywords: m-Government, Mobile Technology, Personalization, User Need

\section{Introduction}

Mobile technologies have become a part of everyday life. Users of mobile technologies do not only want to be connected on the go, but they also want to receive personalized information. For example, they need to get updated about the local weather, local news, and information related to their specific profiles, interests, and preferences.

These unique requirements of the mobile users give rise to a new concept in the technological world. The concept is popularly known as personalization of M-government services. In the technologically advanced world of today, governments are required to deliver m-government services that are tailored to individual needs to make it easier for them to use the services anytime and anywhere ${ }^{1,2}$. M-Government services, is one of the government's initiatives for citizens to provide quick and easy access to the information at anytime and anywhere. Furthermore, the information is more convenient and accessible to be accessed in which there is real-time access to $\mathrm{m}$-Government and personalization maximizes the benefits of accessing information using mobile application.

Personalization is referred to the use of information provided by the citizens in producing better designs in products and services that satisfy the needs of citizens $s^{3,4}$. In mobile application, personalization is a vital element to offer the services in accordance with the needs and preferences of users ${ }^{5-7}$. Many researchers have come forward and reflected that personalization is able to provide the best services to users by providing services that meet the needs and preferences of the users with an efficient and effective manner ${ }^{8-10}$.

${ }^{*}$ Author for correspondence 
The government of Malaysia has significantly contributed to this by launching initiatives based on electronic government programs termed as e-KL. It is a considerate effort of interlinking numerous service delivery agencies in order to benefit civilian and businesses effectively likewise within the vicinity of Klang Valley. e-KL provides services to all government agencies by focusing on the principle of "one government, many agencies".

Furthermore, the penetration of mobile phones in Malaysia has increased its usage compared to the use of personal computers. This is an opportunity for the government to provide the best $\mathrm{m}$-Government services for its citizens. The highest mobile penetration can be seen in Klang Valley compared to other areas, as most citizens there are aware and use the M-government services provided by the government ${ }^{11-13}$.

In Malaysia, although there are numerous services offered by the government to the citizens, the use of these services has been low ${ }^{14}$. Hence, it can be argued that there is limited researches which are focused on services to the individual needs of each citizen ${ }^{15,16}$. With the increasing number of $\mathrm{m}$-Government services offered, the use of $\mathrm{m}$-Government has also increased annually. It has been difficult for citizens to find an appropriate service according to their needs and interests. They prefer services that are easy to use, can be accessed anytime and at anywhere, and more personalized ${ }^{11}$.

Furthermore, information overload occurs when a user receives exceeding amount of information. This makes it difficult for users to reach relevant information quickly and easily ${ }^{17}$. Thus, in order to overcome the problem of information overload and to provide the best services based on the user needs, further study is permitted to help the government providing the personalization application.

As a result, the government should take immediate steps to get closer to the citizens by offering more accessible and more personalized services, based on interests and needs to increase the use of the services ${ }^{18-20}$. Thus, the purpose of this study was to examine citizens' level of use towards $\mathrm{m}$-Government services and to suggest the personalization strategies that help the government to provide better services to the citizens.

\section{Methodology}

The survey method was obtained in this study to know the level of used m-Government among citizens and to know the user's needs/interest towards m-government services. The unit of analysis for this study was the citizens aged 18 and above who used the m-Government services at five selected agencies. The questionnaire consisted of two parts; the first part covered questions related to personal information, and the second part was towards the level of use of $\mathrm{m}$-Government services.

For data collection purposes, 200 questionnaires were distributed at five agencies which are: JPN, JPA, KPDNKK, MOE and MPM. The demographics information captured in this study were age, gender, status, education level, mobile device used, user category and internet access method. The respondents were between the ages of 18 and 24 years old, which recorded the highest percentage followed by the age of 25-40 years. This younger generations were the most potential users using $\mathrm{m}$-Government as they are exposed to the use of latest mobile technologies nowadays. In this study, the analysis was conducted using a statistical analysis (SPSS 20.0).

\section{Result}

For the purpose of this study, we listed 46 types of services for the respondents to state their level of use towards those $\mathrm{M}$-Government services. In general, the results reveal that the levels of respondents' use towards $\mathrm{m}$-Government services are encouraging but most respondents only utilized one service for each transaction. They also did not know the appropriate services suitable for their needs.

The government has offered five types of m-government services to its citizens, including my SMS, my USSD, my MMS, and my App and myPay. However, mySMS is a service that is widely used by the respondents compared with the 4 types of services offered as shown in Figure 1. MySMS indicated the highest percentage which was $39.5 \%$, followed by myMMS (22.5\%), myUSSD (17.5\%), myApp (15.5\%) and myPay (5\%). MyPay is the new service which started to be offered by the government to public since December 2013 and there are five agencies that pioneered this service. They are my Payment of MGX (Malaysia Government ExchangeMAMPU), Federal Territory Zakat Collection Centre, Property Management Division (CPD), Council Melaka Historical City (MBMB) and Subang Jaya Municipal Council (MPSJ). This platform makes it easier for the citizens to get the government information using mobile devices and citizens are provided with the free counter application. 


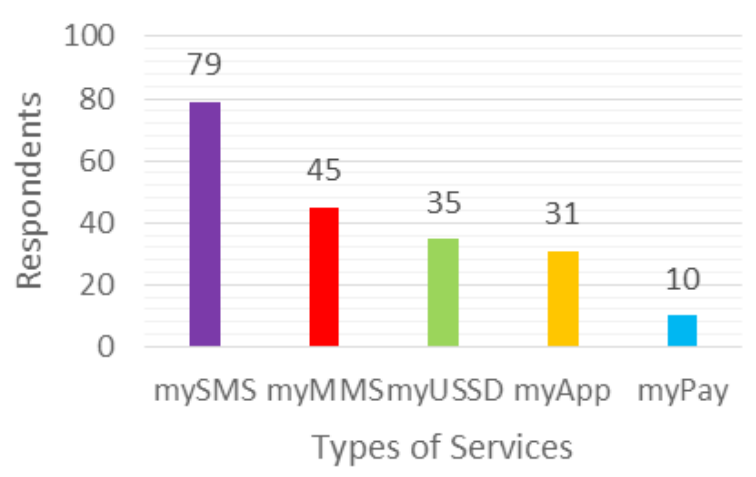

Figure 1. Types of m-Government Services used by Respondents

Table 1 shows the 10 types of services that are used by majority of the respondents. The highest type of services chosen by most respondents was checking the application status for my KAD, followed by checking SPM result, checking MUET result, checking the application for admission to IPTA, checking JPJ summon, checking KPDNKK complaint, checking KPDNKK user tribunal, checking blacklist driving license, checking blacklist vehicle registration license and checking expired date for driving license. Checking the expired date for driving license was the least popular type of services chosen by the respondents, with only $45.6 \%$ respondents.

The respondents were also asked to give their suggestions on what needs to be improved in m-Government services. Table 2 shows the frequencies of the elements that were suggested by respondents. Majority of the respondents needs the personalized application for $\mathrm{m}$-Government, where it is shown as the highest suggestions, rated at $82.3 \%$, whereas, only $74.4 \%$ and $70.2 \%$ respondents' suggestions are related to the quality of mobile services and security respectively.

Table 3 shows the level of use of $\mathrm{m}$-Government services based on the purpose of using the services. The respondents used the $\mathrm{m}$-Government services were mainly for making complaint, checking, assessing information, receiving services from the departments, and applying for applications. Checking (29.0\%) and assessing information/ advisory service (28.5\%) were noted to be the most used services by the respondents. Other than that, $18.5 \%$ of the respondents applied for applications elsewhere, as opposed to students, especially the ones taking SPM and STPM used these services in applying for the IPTA and polytechnic to further their studies. However, making
Table 1. Respondents' level of use towards m-government services

\begin{tabular}{|c|c|}
\hline Types of Services & $\%$ \\
\hline Check application status for myKAD & 90.3 \\
\hline Check SPM result & 86.4 \\
\hline Check MUET result & 84.7 \\
\hline Check JPJ summon & 80.4 \\
\hline Check KPDNKK complaint & 78.1 \\
\hline Check KPDNKK user tribunal & 76.8 \\
\hline Check blacklist driving license & 70.2 \\
\hline Check blacklist vehicle registration license & 68.5 \\
\hline Check expired date driving license & 45.6 \\
\hline
\end{tabular}

Table 2. Respondents' suggestion toward m-government services

\begin{tabular}{|c|c|}
\hline Element & $\%$ \\
\hline Improve ease of use & 80.6 \\
\hline Provide reliable and accurate information & 76.3 \\
\hline Develop personalized application & 82.3 \\
\hline Provide information based on locations & 79.8 \\
\hline Improve quality of mobile services & 74.4 \\
\hline Improve security & 70.2 \\
\hline
\end{tabular}

Table 3. The level of use m-government based on the purposes of using the services

\begin{tabular}{|c|c|}
\hline Element & $\%$ \\
\hline Making complaints & 12.0 \\
\hline Checking information & 29.0 \\
\hline Accessing information or advisory service & 28.5 \\
\hline Receiving service from departments & 12.0 \\
\hline Applying for applications & 18.5 \\
\hline
\end{tabular}

complaints and receiving services from departments contributed the similar percentages which $12.0 \%$.

Table 4 presentsthedemographicprofileofrespondents. It was found that majority of the respondents that used $\mathrm{m}$-Government services is between the ages of 18-24 years (28.5\%) and $25-40$ years (26.5\%). In total, $51.0 \%$ respondents were males and $49.0 \%$ were females. More than half of the respondents are married (50.5\%). Those who are single constitutes $49.0 \%$ and $0.5 \%$ are divorced. In general, most of the respondents have graduated with degree bachelor degree (31.0\%), 19.5\% graduated with diploma, $18.0 \%$ from STPM, 15.5\% from SPM, 11.0\% graduated 
Table 4. Personal profile of respondents $(n=200)$

\begin{tabular}{|c|c|c|c|}
\hline Variable & Categories & $\mathbf{N}$ & $\%$ \\
\hline \multirow{5}{*}{ Age } & $<18$ & 27 & 13.5 \\
\hline & $18-24$ & 57 & 28.5 \\
\hline & $25-40$ & 53 & 26.5 \\
\hline & $41-55$ & 38 & 19.0 \\
\hline & $>55$ & 25 & 12.5 \\
\hline \multirow{2}{*}{ Gender } & Male & 102 & 51.0 \\
\hline & Female & 98 & 49.0 \\
\hline \multirow{3}{*}{ Status } & Single & 98 & 49.0 \\
\hline & Married & 101 & 50.5 \\
\hline & Others & 1 & 0.5 \\
\hline \multirow{6}{*}{$\begin{array}{l}\text { Education } \\
\text { Level }\end{array}$} & PHD & 10 & 5.0 \\
\hline & Master & 22 & 11.0 \\
\hline & Degree & 62 & 31.0 \\
\hline & Diploma & 39 & 19.5 \\
\hline & STPM & 36 & 18.0 \\
\hline & SPM & 31 & 15.5 \\
\hline \multirow{3}{*}{$\begin{array}{l}\text { Mobile } \\
\text { Device }\end{array}$} & Mobile Phone & 127 & 63.5 \\
\hline & Personal Digital Assistant & 24 & 12.0 \\
\hline & Tablet/ iPAD & 49 & 24.5 \\
\hline \multirow{5}{*}{$\begin{array}{l}\text { User } \\
\text { Category }\end{array}$} & Government & 59 & 29.5 \\
\hline & Private & 40 & 20.0 \\
\hline & Student & 47 & 23.5 \\
\hline & Business Partner & 16 & 8.0 \\
\hline & Public & 38 & 19.0 \\
\hline \multirow{2}{*}{$\begin{array}{l}\text { Internet } \\
\text { Access } \\
\text { Method }\end{array}$} & Wi-fi & 122 & 61.0 \\
\hline & Data Plan & 78 & 39.0 \\
\hline
\end{tabular}

with a master's degree and $5.0 \%$ graduated with a PHD degree. In this study, $63.5 \%$ used mobile phone, $12.0 \%$ used personal digital assistant and $24.5 \%$ used tablet/ $\mathrm{iPAD}$ to access the $\mathrm{m}$-Government services. The government servants were the majority respondents that used the m-government services (29.5\%), followed by students (23.5\%), private $(20.0 \%)$, public (19.0\%) and business partners (8.0\%). Lastly, the Wi-Fi shows the highest percentage of internet access method (61.0\%) for accessing the government information.

\section{Discussion}

This study demonstrates that although the government has provided various services to the citizens and many citizens are willing to use the services, the use of the services has been unfavorable. Studies demonstrated that the majority of respondents in Malaysia have used the $\mathrm{m}$-Government services provided by the government, but only utilized at least one service in each transaction. However, the increasing rates of penetration and use of mobile devices in Malaysia have a positive impact on the implementation of government services. Due to this, government should take this opportunity to focus on the user needs and offer the personalization application to encourage the usage of $\mathrm{m}$-Government services among citizens.

The following strategies can help the Malaysian government to personalize the respective aspects and functionalities of deploying the perfect government environment for its individual users.

\section{Mobile Payment Infrastructure}

Deploy Mobile Payment Services in order to acquire successful implementation of M-government. Ensure security measures by gaining the consent of the general public, since most citizens mistrust online resources for conducting payment transactions ${ }^{21}$. Securing a network infrastructure that accommodates the credit card information of individual would sufficiently gain the trust and promote the M-payment services more effectively.

\section{Aspects of Privacy and Security}

Government organizations should standardize the M-government environment that provides individuals the opportunity to securely transfer personal information within the M-government network infrastructure. The greater mistrust that has significantly evolved among individuals is related to the security issues where they fear that their respective information is going to be transferred to a third party.

\section{Make It User-Friendly}

A successful implementation of M-government depends on its functionalities that offer a user-friendly interface for its users. A user-friendly interface would help individuals to stay interlinked with the current government happenings and moreover, keep them considerably involved with the software service.

\section{Establish Laws and Regulation}

Government agencies should observe a standard framework for deploying mobile government far and wide across the vicinity of Malaysia. Government regulations and policies would ensure the consequences that individuals can significantly face in using the services for unethical activities or misconducts. 


\section{M-Government Compatibility and Interoperability}

Design the services and interface in such a manner that is the services are compatible and interoperable with every mobile device. Compatibility is the main aspect since it helps individuals to avoid complexities of slow processing and ineffective mitigation. An effective solution is to deploy an open resource system using non-propriety standards.

\section{Conclusion}

This study aims to investigate the use of $\mathrm{m}$-Government services and propose strategies for promoting the use of personalization service among citizens. The analysis undertaken indicated that although citizens are aware of $\mathrm{m}$-government service, the level of use of $\mathrm{m}$-Government still unfavourable and citizens did not know the appropriate services based on their needs because they only used the basic and familiar services to them. From the analysis, it was found that most youngsters used the $\mathrm{m}$-Government services offered by the government. The respondents were between the ages of 18 and 24 years old, which recorded the highest percentage, followed by the ages of 25-40 years. The youngsters were the users who mostly used m-Government services because they are familiar with the mobile technologies and used this platform for searching the information.

In addition, the government should take immediate steps to provide the personalization services to the citizens to encourage the usage of $\mathrm{m}$-Government services. They also should provide the m-government service that is appropriate based on user needs. Finally, we can state that personalization strategies are one of the solutions that can be used to overcome the information overload problems and to obtain the high level of citizens' satisfaction towards $\mathrm{m}$-Government services.

\section{References}

1. Kushchu I, Kuscu M. From E-government to M-government: Facing the Inevitable, Proceeding European Conference of E-Government (ECEG 2003), 2004, p. 1-12.

2. AlRazooqi M, Silva R De. Mobile and Wireless Services and Technologies for M-Government Solution Proposal for Dubai Government. J WSEAS Transition on Information Science and Application. 2010; 7(8):1037-47.

3. Ivan I, Sacuiu L, Milodin D, Georgescu M. The Development of Citizen Oriented Informatics. Informatic Economic. 2010; 14(4):183-95.
4. Eight Steps To Great Customer Experiences for Government Agencies. http://www.oracle.com/us/ products/applications/8-steps-cust-exp-gov-wp-1560471. pdf. Date accessed: March 2012.

5. Reis JL, Carvalho JÁ. Aspects that contribute to the success of personalized Web applications. Advances in Information Systems and Technologies. 2013, p. 1-12.

6. Germanakos P, Samaras G, Mourlas C, Christodoulou E. Innovation Personalization Issues for Providing UserCentric M-Government Services, 6th International Conference on Electronic Government (E-Gov 2007), 2007, p. 1-10.

7. Cho S, Kim J, Ha B. A Solution to Privacy Violation Problem in Korean Ubiquitous Government Service. Indian Journal of Science and Technology. 2015 Oct; 8(25):1-68.

8. Rocha L, Correia AM, Wilson T, Stroetmann KA. Advances in Intelligent Systems and Computing: Preface. Advances in Intelligent System and Computing. 2013; 206:421-32.

9. Bucci D. The Power of Personalization: Optimizing Customer Self-Service for Increased Loyalty and Cost Savings, 2012, p. 13.

10. Germanakos P, Mourlas C, Samaras G. Considering the new user requirements for apt mobile internet services delivery, Proceeding on IADIS International Conference, 2005 , p. 1-8.

11. Al-Thunibat A, Zin N, Sahari N. Identifying User Requirements of Mobile Government Services in Malaysia Using Focus Group Methodology. Journal of E-Government Studies and Best Practice. 2011; 2011:1-14.

12. Mokhlis S. Consumer Choice Criteria in Mobile Phone Selection: An Investigation of Malaysian University Students. International Review on Social Science and Humanities. 2012 Jan; 2(2):203-212.

13. Faziharudean TM, Li-ly T. Consumers behavioral intentions to use mobile data services in Malaysia, African Journal on Business and Management. 2011 Mar; 5(5):1811-1821.

14. Al-Thunibat A, Mat Zin NA, Sahari N. Mobile Government Services in Malaysia: Challenges and Opportunities, Information Technology (ITSim), 2010 International Symposium, 2010 Jun, 3, p. 1244-49.

15. Carroll J. Risky Business: Will Citizens Accept M-government in the Long Term? Euro m-Government, 2005, p. 77-87.

16. Ishmatova D. Assessing User Needs for $\mathrm{m}$-Government Services - A Case Study of Information Mobile Campus Services, International Conference on Theory Practice and Electronic Governance, 2007 Dec, p. 445-446.

17. Zou Y, Webster J. Information overload in using content management systems: Causes and consequences, Proceeding - Pacific Asia Conference Information System, 2014, p. 1-10. 
18. Trimi S, Sheng H. M-GOVERNMENT. Communications of ACM. 2008 May; 51(5):53-58.

19. Schwester R. Examining the Barriers to e-Government Adoption. Electronic Journal of e-Government. 2009; 7(1):113-122.
20. Nava AS. M-Government for Digital Cities, Value Added Public Services. In: Proceedings of the First European Mobile Government Conference, 2005 , p. 304-312.

21. Jahanshahi AA, Khaksar SMS, Yaghoobi NM, Nawaser K. Comprehensive model of mobile government in Iran. Indian Journal of Science and Technology. 2011 Sep; 4(9):1188-1197. 